\title{
INTELECTUAIS CATÓLICOS: CONFIDENTES DO CRIADOR, MINISTROS DO PROGRESSO E SACERDOTES DA VERDADE
}

\author{
Névio de Campos*
}

\begin{abstract}
RESUMO
Este artigo objetiva discutir as estratégias da elite intelectual católica para organizar e divulgar seu ideário filosófico-teológico no Estado do Paraná nas décadas de 1940 e 1950, cujo recorte privilegia a intervenção do laicato católico no Ensino Superior curitibano, pois em tal período se constituíram a Faculdade de Filosofia, Ciências e Letras do Paraná - FFCL (1938) e a Faculdade Católica de Filosofia de Curitiba - FCFC (1950). O problema central consiste em discutir o papel dos intelectuais e o lugar das Faculdades de Filosofia no processo de expansão do ideário católico entre os paranaenses. A narrativa deste artigo apoia-se nos discursos pronunciados na FFCL e na FCFC no decorrer dessas décadas, por meio dos quais o grupo católico reafirmava que o papel dos intelectuais consistia em ser confidentes do Criador, ministros do progresso e sacerdotes da verdade. Esse percurso analítico inscreve-se na história intelectual, estabelecendo interlocução com o conceito de intelectual como organizador da cultura e mobilizador dos grupos sociais. Tal conceito nos permite discutir as iniciativas dos intelectuais católicos no processo de criação, coordenação e direção das atividades formativas organizadas nas Faculdades de Filosofia, bem como problematizar suas ações como estratégias para consolidar a presença do ideário religioso na alta cultura curitibana e contrapor-se aos adversários e inimigos da Igreja Católica.
\end{abstract}

Palavras-chave: Intelectuais. Ensino Superior. Formação humana.

\begin{abstract}
This article discusses the strategies used by the Catholic intellectual élite when organizing and spreading their philosophical and theological ideas in the state of Paraná during the 1940s and 1950s. The focus rests on the Catholic laity's intervention on higher education in Curitiba. It was at that

\footnotetext{
* Doutor em Educação pela Universidade Federal do Paraná. Professor do Programa de PósGraduação em Educação e Professor no Mestrado em História da Universidade Estadual de Ponta Grossa.E-mail: ncampos@uepg.br
} 
time that the Faculties of Philosophy, Science and Arts of Paraná - FFCL (1938) and the Catholic Faculty of Philosophy of Curitiba - FCFC (1950) were constituted. The main problem lies in discussing the intellectuals' role and that of the Faculties of Philosophy in the process of expanding the Catholic ideas among the population of Paraná. This article bases itself on the speeches given at the FFCL and FCFC during these decades in which the Catholic group reasserted that the intellectuals' role consisted in being the creator's confidants, ministers of progress and truth. This analytical course is a part of intellectual history, establishing a dialogue between the concept of the intellectual as a cultural organizer and inspiring social. Such a concept allows us to discuss the initiatives taken by the Catholic intellectuals during the process of creation, coordenation and directing the formative activities organized by the Faculties of Philosophy as well as discussing strategies to consolidate the religious ideals in the high society of Curitiba and oppose the opponents and enemies of the Catholic Church.

Keywords: Intellectuals. Higher education. Human formation.

\section{Introdução}

A assertiva sociológica de que os projetos educativos são construídos socialmente é um pressuposto fundamental às investigações das ciências humanas. Afirmar tal proposição é um avanço significativo, pois desnaturaliza as propostas formativas, entretanto, é uma pressuposição limitada. É preciso nuançar tal indicação, isto é, faz-se necessário problematizar que o processo de construção social é marcado pela disputa entre diferentes grupos pelo poder de organizar os espaços sociais. A noção de construção social tem um sentido heurístico à medida que as análises discutam a vinculação dos grupos às estruturas sociais, assim como às conjunturas do mundo social. Nesse sentido, ao conceito de construção social acrescenta-se a categoria de tempo, objetivando constituir uma abordagem que associe as assertivas de que os projetos educativos são construções sociais e históricas.

A partir desses pressupostos da Sociologia e História pretendemos reconstituir alguns aspectos do processo de organização dos intelectuais católicos, privilegiando suas ações no campo do ensino superior no 
Paraná. O recorte desta análise diz respeito ao problema do ensino superior paranaense, porém, não deixa de considerar que as lutas empreendidas pelos católicos estavam associadas aos diversos espaços sociais. Desse modo, recuperamos a afirmação de Bourdieu (2009, p. 26) de que "o espaço social, bem como os grupos que nele se distribuem, são produto de lutas históricas (nas quais os agentes se comprometem em função de sua posição no espaço social e das estruturas mentais através das quais eles apreendem esse espaço)". A rigor, quais lutas foram travadas pelos católicos para assumir o controle das Faculdades de Filosofia no Paraná? Contra quais grupos organizavam tal disputa? Que estratégias estabeleceram para esse confronto? O enredo deste texto está estruturado a partir desses três questionamentos, pois entendemos que assim teremos condições para sustentar a hipótese de que as Faculdades de Filosofia representam a institucionalização do grupo católico no campo do ensino superior paranaense, bem como o locus de ação e disputa pela definição do papel social da Universidade e dos intelectuais, assim como pelo controle do discurso público das ciências humanas.

A presente investigação apoia-se no conceito de intelectual como organizador da cultura, isto é, compreende que o laicato católico esteve comprometido com o projeto político-pastoral da Igreja Católica, pois organizou diferentes instituições culturais e políticas, objetivando contribuir com o processo de instauração da doutrina católica nas terras paranaenses. A rigor, conforme Névio de Campos (2010, p. 29), "no Estado do Paraná o projeto de romanização do catolicismo foi iniciado de maneira decisiva a partir dos anos de 1890, com a criação da diocese de Curitiba". Entretanto, assevera o autor que "a partir da década de vinte iniciou em nível nacional ${ }^{1}$, bem como no Paraná, o processo de constituição do laicato católico" (CAMPOS, 2010, p. 29). Em Curitiba, os intelectuais estabeleceram a União de Moços Católicos (1926), a Revista A Cruzada (1926), o Círculo de Estudos Bandeirantes - CEB (1929), a Faculdade de Filosofia, Ciências e Letras - FFCL (1938) e Faculdade Católica de

1 Entre os estudos que têm a Igreja Católica como problema de investigação, destacamos Sérgio Miceli (1974), Euclides Marchi (1989), Roberto Romano (1991), Romualdo Dias (1993), Ivan Manoel (1996), Marta Carvalho (1998), Marcus Bencostta (1999) e Bernadete Strang (2008). 
Filosofia - FCFC (1950). Tais espaços representaram a institucionalização de um grupo que esteve à frente de inúmeras atividades no campo da política, da cultura e da educação. É nesse sentido que tomamos o conceito de intelectual como agente social, organizador da cultura e intérprete das visões de mundo como hipótese para problematizar a intervenção do grupo católico no campo do ensino superior do Paraná, pois mais do que escritor de obras desinteressadas ao modo de teóricos acadêmicos, estava envolvido com projetos que buscavam consolidar a presença do pensamento religioso e da filosofia católica entre os paranaenses.

$O$ investimento na criação da diocese de Curitiba, de colégios católicos e na sistematização de espaços culturais de divulgação do ideário religioso e de encontro das lideranças políticas comprometidas com a Igreja, evidencia que existiam outros grupos sociais na capital do Paraná que professavam diferentes visões de mundo. Os estudos acadêmicos indicam que, entre o final do século XIX e as primeiras décadas do XX, houve forte embate entre anticlericais e católicos ${ }^{2}$. A historiografia paranaense é o pano de fundo para problematizar a indagação referente aos adversários dos católicos no Paraná. Entretanto, é fundamental afirmar que os inimigos não eram apenas os grupos que professavam o ideário do laicismo, mas também os próprios católicos que desconheciam a doutrina do catolicismo. Sobre esse aspecto Romualdo Dias (1993, p. 110) sustenta que "[...] o combate tinha como alvo dois tipos de inimigos: os externos e os internos. Os primeiros eram os inimigos da Igreja. Os segundos eram os próprios católicos que se deixavam impregnar pelo "espírito acomodatício"”.

Os debates entre católicos e anticlericais ganharam notoriedade nas páginas da imprensa e nos círculos culturais curitibanos, assim como na tribuna da Assembleia Legislativa ${ }^{3}$. Segundo Névio de Campos (2010, p. 19), "nos debates, que ocorreram nos círculos de intelectuais curitibanos,

2 Carlos Alberto Balhana (1981) e Etelvina Maria de Castro Trindade (1996) retratam o confronto entre clericais e anticlericais no Paraná. Tatiana Dantas Marchette (1999), Maria Lúcia de Andrade (2007) Ernando Brito G. Junior (2011) discutem as ações dos anticlericais. Já Soleni Terezinha Fressato (2003), Névio de Campos (2005; 2007; 2008; 2010a; 2010b; 2011a; 2011b) e Teodoro Hanicz (2006) problematizam as intervenções dos católicos na capital do Paraná.

3 Consultar o artigo "Debate sobre o ensino religioso na capital paranaense: entre a tribuna e a imprensa (1922-1931)", de Névio de Campos (2011b). 
a educação recebeu grande importância. [...] As escolas públicas, particularmente, o Gymnasio Paranaense e a Escola Normal foram palcos de disputas entre o grupo anticlerical e o laicato católico"4. Alguns professores dessas escolas, entre os quais destacamos Dario Vellozo, opunham-se ao ideário católico, aos dirigentes eclesiásticos e às instituições católicas. $\mathrm{O}$ confronto aos católicos, a partir da década de 1930, esteve vinculado ao movimento pela escola nova. Os católicos agiam do interior do CEB, da FFCL e FCFC. Por outro lado, os defensores do ideário da escola nova realizavam sua cruzada de dentro da Escola Normal do Paraná/Instituto de Educação, um dos espaços de ação do grupo defensor do laicismo na educação, particularmente pela atuação de Erasmo Pilotto. Essa assertiva é corroborada por Vieira e Marach (2007, p. 270):

No contexto paranaense, entre os intelectuais vinculados ao movimento renovador, Erasmo Pilotto se destacou de maneira singular. Não foi o primeiro nem o último a defender os princípios do movimento, mas vinculou-se de maneira intensa a esse projeto por meio da sua atuação como professor, organizador de escolas, administrador público e, sobretudo, produtor de uma vastíssima obra pedagógica [...].

Em síntese, sob o pano de fundo do conflito entre defensores da educação laica e do projeto educativo católico, este texto problematiza a ação dos católicos no ensino superior do Paraná. É nesse contexto histórico, marcado pela disputa entre projetos societários e educativos que os intelectuais católicos paranaenses, na precisa denominação de José Loureiro Fernandes ${ }^{5}$, afirmavam-se confidentes do criador, ministros do progresso e sacerdotes da verdade.

4 Etelvina Trindade (1996), Maria Lúcia de Andrade (2007), Aurélio Bona Junior e Carlos Eduardo Vieira (2007), Jean Carlo Moreno (2003), Carlos Eduardo Vieira e Caroline Marach (2007), Elyane Padial (2008), Névio de Campos (2008; 2010a; 2010b; 2011a; 2011b), Ernando Brito Junior (2011) discutem especificamente as ações de clericais e anticlericais no campo da educação.

5 Loureiro Fernandes nasceu em Lisboa no dia 12 de maio de 1903 e faleceu em Curitiba no dia 16 de fevereiro de 1977. Formado em Medicina pela Faculdade do Rio de Janeiro. Ele participou na criação de várias instituições do Paraná como, por exemplo, do Círculo de Estudos Bandeirantes, da Faculdade de Filosofia, Ciências e Letras do Paraná (1938), da Faculdade Católica de Filosofia de Curitiba (1950), da Universidade Federal do Paraná (1950) e da Universidade Católica do Paraná (1959). 


\section{Faculdade de filosofia: espaço de intervenção dos intelectuais católicos no Paraná}

A presença da Igreja Católica na história da educação brasileira é marcante em todos os graus de ensino. Ela recebeu da Corte portuguesa a concessão para coordenar o projeto educativo durante a Colônia, embora a metrópole tenha impedido a criação de faculdades e universidades ao longo daquele período. No decorrer do Império, as relações entre poder civil e poder eclesiástico eram oficiais, pois o sistema do padroado expressava a relação indissociável entre Igreja e Império. Por um lado, a Igreja usufruiu dos benefícios de ser a religião oficial do Estado ao acumular significativo capital econômico, capital político e capital simbólico. Por outro, esteve controlada pelo poder civil. Apesar disso, houve ao longo da segunda metade do século XIX diversos confrontos entre esses dois poderes.

A República, do ponto de vista formal, consubstanciou a ruptura entre Igreja e Estado. Com a nova conjuntura política, a Igreja sofreu algumas perdas, entre as quais destacamos o fim da condição de religião oficial do Estado. Em decorrência disso, as esferas públicas deveriam excluir os símbolos do catolicismo, como por exemplo, a retirada do ensino religioso das escolas públicas. Em contrapartida, a Igreja não precisava de autorização do poder civil para organizar dioceses, criar seminários e trazer congregações religiosas para o Brasil, o que contribuiu para o avanço institucional da religião católica no território brasileiro. A primeira iniciativa foi a expansão de dioceses e arquidioceses, resultando concomitantemente na vinda de ordens religiosas europeias para assumirem projetos sociais e educacionais. Outra estratégia da Igreja Católica, conforme Romualdo Dias (1993, p. 2), foi "a formação de uma elite intelectual a serviço do projeto político-pastoral do episcopado".

No final do século XIX, a Igreja Católica assumiu, no Brasil, as orientações emanadas de Roma - movimento denominado romanização - que consistia em forte disciplinarização do clero e criação de inúmeras estratégias político-pastorais. Uma dessas estratégias foi estimular a organização do laicato católico, a qual se consolidou com o processo de criação de centros culturais para aglutinar e formar uma elite intelectual e política no país, comprometida com o ideário católico romanizador. Nesse 
aspecto, a diocese deveria fomentar a vinda de ordens religiosas, criação de escolas, hospitais, projetos socioassistenciais, bem como de jornais, revistas e espaços de estudos e formação moral, filosófica e teológica dos grupos com potencialidade a ocuparem cargos políticos de destaque nos cenários regionais, assim como no nacional.

A estratégia de criação do laicato católico consistia em uma ação direcionada a uma pequena parcela da população brasileira, ou seja, aglutinar e formar um grupo de intelectuais e políticos comprometidos com o ideário católico. A ação "pelo alto" visava formar a juventude com base nos fundamentos filosóficos e teológicos da Igreja Católica, cuja missão foi atribuída aos centros superiores de cultura.

No Brasil, esse projeto esteve sob a coordenação do episcopado brasileiro, particularmente sob a orientação de Dom Sebastião Leme. Na capital da República, esse arcebispo formou um grupo de intelectuais em torno do Centro Dom Vital e da Revista A Ordem. No Paraná, a organização do laicato católico esteve sob a responsabilidade da Diocese de Curitiba, criada em 1892. Os diferentes projetos que contaram com presença significativa do laicato eram dirigidos por representantes do clero. Em 1926, foram criadas a União de Moços Católicos de Curitiba e a Revista A Cruzada, sob a coordenação do Padre Antônio Mazzarotto (futuro Bispo da Diocese de Ponta Grossa) ${ }^{6}$. Em 1929, foi estabelecido o Círculo de Estudos Bandeirantes, composto majoritariamente por leigos, não obstante, sob a coordenação do Padre Luiz Gonzaga Miele?

A elite intelectual católica teve uma atuação significativa na elaboração de projetos formativos nas décadas de 1920 e 1930. A sua trajetória se estruturou de maneira clara com a liderança de D. Leme. Na mesma direção da Arquidiocese do Rio de Janeiro, a Diocese de Curitiba

\footnotetext{
6 Antônio Mazzarotto nasceu em Curitiba em 1 de dezembro de 1890 e faleceu em Ponta Grossa em 15 de julho de 1980. Foi bispo de Ponta Grossa entre 1929 e 1965.

7 Luiz Gonzaga Miele nasceu em São Bernardo do Campo no dia 31 de maio de 1893. Concluiu sua formação filosófica e teológica em Paris. Em 1924, foi nomeado professor do Ginásio Paranaense, na seção internato, professor de lógica, psicologia e história da filosofia, o que evidencia a estreita relação entre Igreja e Estado no governo de Caetano Munhoz da Rocha. Padre Miele dirigiu o CEB até dezembro de 1932, quando se transferiu para São Paulo.
} 
estruturou o seu clero e estabeleceu as diretrizes para a formação dos intelectuais católicos leigos. Foi a partir do final da década de 1920 que o grupo católico passou a lutar efetivamente pelo controle do ensino superior no Brasil. Naquele momento, "segundo o ideário católico, a reforma na consciência das elites só se operacionalizaria, basicamente, através do sistema de ensino superior. Ou seja, a cosmovisão católica percebe a universidade como centro nevrálgico de toda a estrutura social" (SALEM, 1982, p. 128). Os católicos se aproximavam do Estado a fim de manter a presença de sua visão no mundo social e, ao mesmo tempo, já expressavam o desejo de implantar o sistema particular de ensino superior. Ou seja, não dispensavam a boa relação com o Estado, mas também não acreditavam absolutamente na aliança com o poder civil. No Paraná, no governo de Caetano Munhoz da Rocha (1920-1928) foi estreita a relação entre Igreja Católica e Estado ${ }^{8}$. Nos anos de 1930 e 1940, as relações entre Estado e Igreja continuaram amistosas, principalmente pelas aproximações existentes entre Loureiro Fernandes e Manoel Ribas9. Na década de 1950, a Igreja Católica manteve significativo vínculo com o poder civil, particularmente no governo de Bento Munhoz da Rocha Neto ${ }^{10}$.

A constituição de faculdades católicas era orientada pelos documentos oficiais da Igreja. Em 1934, no Rio de Janeiro, organizaram o Primeiro Congresso Católico de Educação, no qual Alceu Amoroso Lima reiterava o papel do laicato no processo de organização de projetos formativos, sobretudo ao fundar instituições de ensino superior. Esse congresso foi promovido pela Coligação Católica Brasileira, quando foi declarada a necessidade de criar uma universidade subordinada à Santa Sé e ao episcopado brasileiro. Em 1939 foi realizado o Primeiro Concílio

8 Caetano Munhoz da Rocha nasceu em Antonina no dia 14 de maio de 1879 e faleceu em Curitiba no dia 23 de abril de 1944.

9 Manoel Ribas nasceu em Ponta Grossa no dia 8 de março de 1873 e faleceu em Curitiba no dia 28 de janeiro de 1946. Esteve à frente do Governo do Paraná no período de 1932 a 1945 (interventor de 1932 a 1934 e 1937 a 1945; governador de 1935 a 1937).

10 Bento Munhoz da Rocha Neto nasceu em Paranaguá no dia 17 de dezembro de 1905 e faleceu em Curitiba no dia 12 de novembro de 1978. Em 1929, fez parte do grupo católico que fundou o Círculo de Estudos Bandeirantes. Entre 1951 e 1955 foi governador do Paraná. 
Plenário Brasileiro, na Bahia, no qual se expressou a última grande manifestação para criação da universidade católica no Brasil.

A instituição do ensino superior católico fez parte do projeto político da Igreja. No Brasil, a organização católica se consubstanciou no Centro Dom Vital (1921), na Revista A Ordem (1922), na Associação dos Universitários Católicos (1929), no Instituto Católico de Estudos Superiores (1932), na Confederação Nacional dos Operários Católicos, em Equipes Sociais, na Confederação da Imprensa Católica e Associação de Livrarias Católicas, criadas entre 1930 e 1935. Esses organismos constituíam a Coligação Católica Brasileira, criada em 1929. Mais tarde, em 1935, foi substituída pela Ação Católica Brasileira. A ação da Igreja foi representada por outras instituições que não estavam vinculadas à Ação Católica Brasileira, tais como Congregação Mariana, Círculos Operários, Associação dos Professores Católicos, Liga Eleitoral Católica, Confederação Católica Brasileira de Educação. Para Tânia Salem (1982, p. 120), "com a pulverização do Centro Dom Vital em diferentes frentes de trabalho de leigos, subordinadas à Coligação Católica Brasileira, a educação e, em especial, a educação superior se converteu em um domínio especializado do movimento".

O Instituto Católico de Estudos Superiores e a Associação dos Universitários Católicos são considerados os embriões do projeto universitário católico no Brasil. Essas duas instituições, segundo Salem (1982, p. 120),

[...] embora com sentidos bastante distintos, foram as entidades geradas para uma atuação da Igreja do domínio universitário. Essas são, em suma, as instâncias mediadoras que remontam o trajeto entre a eclosão do movimento católico, em 1922, e a fundação das Faculdades Católicas, em 1941.

No Estado do Paraná, a história do ensino superior teve início em 1892, quando Francisco da Rocha Pombo defendeu a criação de uma universidade, recebendo autorização da Assembleia Legislativa, assim como doação, por parte da Prefeitura de Curitiba, de terreno para construção do prédio. Entretanto, a proposta de Rocha Pombo não se materializou. Em 
1912, foi estabelecida a Universidade do Paraná, sob a proteção jurídica da Reforma Rivadavia Correa e a coordenação de um grupo de intelectuais e políticos paranaenses, entre eles Victor Ferreira do Amaral e Nilo Cairo da Silva ${ }^{11}$. Para esse grupo, os profissionais das engenharias, da medicina e do direito deveriam ocupar as esferas estratégicas do estado a fim de organizar reformas que garantissem o progresso e a modernização no mundo social. Nesse aspecto, a contribuição do projeto universitário de 1912 foi fundamental, pois colocou a serviço das instituições sociais um corpo de especialistas com capacidade de sistematizar projetos e programas para as diferentes esferas, particularmente às de economia, infraestrutura, educação e saúde pública. No entanto, em 1915, a Reforma Maximiliano determinou que apenas a União poderia legalmente estabelecer universidades no Brasil. Dessa forma, a Universidade do Paraná foi desmembrada em três faculdades (Engenharia, Direito e Medicina). Somente em 1946 a Universidade do Paraná foi restaurada.

Entretanto, antes da (re)fundação da Universidade do Paraná, a história do ensino superior paranaense foi marcada pela criação da Faculdade de Filosofia, Ciências e Letras. A rigor, essa instituição foi criada em 1938, passando, um ano mais tarde, à coordenação dos católicos (Irmãos Maristas). Embora a Faculdade de Filosofia tenha se estabelecido no final da década de 1930, anteriormente os católicos já se mostravam interessados em organizar espaços de formação filosófica para seus integrantes. Tal hipótese pode ser verificada na história do Círculo de Estudos Bandeirantes, principal órgão de encontro do laicato católico no Paraná, durante a década de 1930. Entre 1934 e 1937, nesse espaço cultural, foi ofertado um Curso de Filosofia Tomista, sob a coordenação do Pe. Jesus Ballarin Carrera, também um dos integrantes do grupo fundador e diretores da Faculdade de Filosofia (CAMPOS, 2008).

Nos anos de 1940 ocorreu o processo de consolidação jurídica da universidade no Estado do Paraná. Essa nova situação resultou da ação dos grupos envolvidos com o ensino superior nesse estado. Em 1946, a Universidade do Paraná foi oficializada com a aglutinação das Faculdades de Medicina, de Engenharia, de Direito e Filosofia, Ciências e Letras. A FFCL continuou sob o controle dos Maristas e do laicato católico, mas compôs o

$\overline{11}$ Sugerimos consultar Névio de Campos (2008) e Rui Wachowicz (1983). 
conjunto de instituições necessárias para estabelecer uma universidade. A constituição da Universidade do Paraná resultou da aglutinação de quatro faculdades, sem uma discussão a respeito dos elementos que definiriam um projeto universitário. É possível afirmar que o interesse administrativo, isto é, a autonomia administrativa, foi o principal argumento para a restauração da universidade. Não houve discussão sobre a caracterização acadêmica de uma universidade. A primeira gestão da reitoria foi composta por um membro da Faculdade de Medicina (Reitor) e outro da Faculdade de Direito (Vice-Reitor). As gestões posteriores deveriam alternar na seguinte ordem: Direito (Reitor) e Engenharia (Vice-Reitor), Engenharia (Reitor) e Filosofia (Vice-Reitor). Essa ordem foi obedecida até a reitoria ser assumida pela Faculdade de Engenharia, pois de 1949 até 1964 Flávio de Lacerda (Engenharia) esteve à frente da reitoria, portanto, foi quebrada a convenção estabelecida em 1946 que previa alternância de reitoria entre as quatro faculdades que deram origem à Universidade do Paraná.

Em dezembro de 1949 foi lançado o movimento pela federalização da Universidade do Paraná. No decorrer de 1950 houve os encaminhamentos legais para o processo de federalização, cuja oficialização aconteceu no dia 19 de dezembro do corrente ano. Os grupos que controlavam o ensino superior repassaram à União, as atribuições de gerir a Universidade do Paraná. A FFCL, cuja mantenedora era a Associação dos Maristas, foi transferida às mãos do Estado brasileiro. Porém, o corpo docente foi mantido e formalmente reconhecido como funcionários do Estado. Portanto, do ponto de vista ideológico a organização da FFCL foi mantida, uma vez que a direção e o corpo docente, em sua grande maioria, tinham vínculos estreitos com a Igreja Católica, isto é, constituíam o laicato católico. Além da manutenção dos docentes e da orientação intelectual na FFCL da Universidade Federal do Paraná, os representantes católicos, antes mesmo da oficialização da federalização, fundaram a FCFC. Em agosto de 1950, o laicato católico e a Congregação Marista estabeleceram a segunda Faculdade de Filosofia no Paraná, no entanto, essa passou a chamar-se, oficialmente, Faculdade Católica ${ }^{12}$.

12 Neste texto não há a pretensão de discutir as histórias da Faculdade de Filosofia, Ciências e Letras do Paraná (1938) e Faculdade Católica de Filosofia de Curitiba. Essa discussão pode ser localizada em Campos (2008; 2010b; 2011a) e Westphalen (1988). 
Em síntese, na primeira metade do século XX constituíram-se várias instituições de ensino superior no Paraná. A história universitária paranaense perpassa pelas experiências de 1912 (fundação da Universidade do Paraná), de 1938 (criação da Faculdade de Filosofia, Ciências e Letras do Paraná), de 1946 (restauração da Universidade do Paraná) e 1950 (federalização da Universidade do Paraná e fundação da Faculdade Católica de Filosofia de Curitiba). Portanto, as Faculdades de Filosofia representam a institucionalização do grupo católico no campo do ensino superior paranaense, bem como o locus de ação e disputa pela definição do papel social da Universidade e dos intelectuais, assim como pelo controle do discurso público das ciências humanas.

\section{Luta pelo monopólio da legitimidade de afirmar a função social da universidade e dos intelectuais}

No item anterior, foi apresentada, de modo sintético, a participação do grupo católico no processo de construção de projetos de ensino superior, problematizando a hipótese de que a Faculdade de Filosofia representou a institucionalização dos intelectuais católicos no debate do contexto paranaense. Neste momento, discutiremos as estratégias dos intelectuais católicos para manter o controle sobre as Faculdades de Filosofia, assim como pelo direito de afirmar, no interior do campo cultural, qual a função social da universidade e do intelectual. A rigor, em nossa interpretação identificamos que o grupo católico estabeleceu as intervenções nas aulas inaugurais, formaturas de colação de grau e publicações como estratégias para conformar a visão do e sobre o campo acadêmico, assim como do mundo social.

Tais espaços de intervenção guardam um sentido cerimonial, particularmente os rituais de aula inaugural e colação de grau, pois ganham sentidos extraordinários. Nesses termos, conforme Bourdieu (2008, p. 28), "os rituais representam o limite de todas as situações de imposição, nas quais, por meio do exercício de uma competência técnica [...], se exerce uma competência social, a do locutor legítimo, autorizado a falar e a falar com autoridade". Em síntese, os discursos proferidos nos rituais de aula inaugural e colação de grau, representam a posição da própria instituição 
social. Em interlocução com Bourdieu (2008, p. 63), sustentamos que "o verdadeiro princípio da magia dos enunciados performativos reside no mistério do ministério, isto é, na delegação ao cabo da qual um agente singular [...] recebe o mandato para falar e agir, em nome do grupo, assim constituído nele e por ele".

Além de formar professores para o ensino secundário, a Faculdade de Filosofia pretendia conformar o próprio mundo social universitário ao postular a prevalência da formação humanista (educação geral) sobre a formação profissional. É nesse sentido que buscamos evidenciar a hipótese de que tal Faculdade tinha por objetivo assumir o controle das humanidades (filosofia, letras e ciências humanas) e a própria definição da função da universidade. Desse modo, entendemos que "o mundo universitário, como todos os universos sociais, é o lugar de uma luta pela verdade sobre o mundo universitário e sobre o universo social em geral" (BOURDIEU, 2009, p. 116). Em termos mais precisos, Pierre Bourdieu (2009, p. 116) assevera que "a universidade [...] é o lugar de uma luta para saber quem, no interior desse universo socialmente mandatário para dizer a verdade sobre o mundo social [...], está realmente (ou particularmente) fundamentado para dizer a verdade".

Nesta narrativa privilegiam-se os discursos de paraninfos, aulas inaugurais e as publicações da FFCL e FCFC, pois eles enfatizam a posição oficial do grupo que controlava tais instituições. $\mathrm{Na}$ assertiva de Bourdieu (2008, p. 82), "o mistério da magia performativa resolve-se assim no mistério do ministério [...], isto é, na alquimia da representação [...] através da qual o representante constitui o grupo que o constitui". Em termos mais precisos, "o porta-voz dotado do poder de falar e de agir em nome do grupo, falando sobre o grupo pela magia da palavra de ordem, é o substituto do grupo que existe somente por esta procuração" (2008, p. 83). Ou ainda, o locutor "recebe o direito de falar e de agir em nome do grupo, de 'se tomar pelo' grupo que ele encarna, de se identificar com a função à qual ele 'se entrega de corpo e alma', dando assim um corpo biológico a um corpo constituído” (2008, p. 83).

As duas Faculdades de Filosofia do Paraná estavam associadas à tradição católica. Entretanto, o projeto da FFCL que ficou sob a coordenação dos Maristas entre 1939 e 1950 não tinha subordinação direta à Arquidiocese 
de Curitiba, pois, conforme seu estatuto, não era confessional. Já a FCFC, dirigida pelos Maristas, estava subordinada diretamente à Arquidiocese de Curitiba que, por meio da Sociedade Paranaense de Cultura, criada em 31 de dezembro de 1950, passou a coordenar o processo de implantação do ensino superior católico no Paraná.

As duas instituições mantinham publicações periódicas. A FFCL publicizava no Anuário, os discursos de paraninfos, as aulas inaugurais e os relatórios. E a FCFC publicava na Revista Humanitas, as orações de paraninfos, aulas inaugurais, os relatórios e artigos de docentes e discentes. Nessas publicações, o pensamento filosófico católico ganhava centralidade. No entanto, na Revista Humanitas a ênfase na tradição católica dava contornos mais precisos. Em nossa avaliação, o caráter confessional oficial - portanto, a relação institucional com a Arquidiocese de Curitiba, conformou uma posição mais unitária à FCFC. Já na FFCL prevalecia a visão católica, no entanto, não havia uma única posição, portanto, a ideia de luta pela verdade sobre o mundo universitário estava em movimento contínuo no próprio interior da FFCL, particularmente após a federalização da Universidade do Paraná. Em nossa avaliação, a aula inaugural de 1951, proferida por Wilson Martins, representa uma das expressões da contraposição ao domínio ideológico do grupo católico na FFCL, pois ele discutiu, na exposição que se intitulava $A$ revolta contra a inteligência e a missão da universidade, a função social da Faculdade de Filosofia e dos intelectuais. A intervenção de Wilson Martins ecoava os dois conceitos (universidade e intelectuais) que povoavam as enunciações do grupo católico, porém sua narrativa dialogava com o pensamento de Ortega y Gasset ${ }^{13}$ e não com a tradição humanista católica ${ }^{14}$. A primeira aula inaugural na FFCL, após a federalização da Universidade do Paraná, foi proferida por um personagem que não professava adesão à tradição

13 Em 1951, a aula inaugural da FFCL foi proferida por Wilson Martins - autor que tinha posição divergente do grupo católico. Em nossa avaliação, essa aula anuncia a relativização do poder da Igreja Católica na FFCL, embora a reitoria da UP e a direção da FFCL estivessem sob a direção de Flavio S. de Lacerda e Homero de Barros, ambos pertencentes ao grupo católico.

14 Consultar Névio de Campos, em Wilson Martins: entre a intelligentsia e a universidade (1951), Revista Brasileira de História da Educação (no prelo). 
filosófica católica. Wilson Martins era professor no Curso de Letras, na cadeira de Literatura Francesa. Esse episódio anuncia a relativização do poder da Igreja Católica na FFCL, embora a reitoria da UP e a direção da FFCL estivessem sob a direção de Flavio S. de Lacerda e Homero de Barros, ambos pertencentes ao grupo católico. O fato de Wilson Martins proferir essa aula inaugural evidencia que a posição dos clericais sofria contragolpes, particularmente após o processo de federalização da Universidade do Paraná.

No quadro abaixo indicamos os nomes de professores que proferiram aulas inaugurais e/ou orações de paraninfo, o que indica a prevalência do grupo católico nesses rituais de consagração.

\section{Quadro 1}

\begin{tabular}{|c|c|c|c|}
\hline \multicolumn{4}{|c|}{ Alguns discursos do corpo docente da FFCL $-1940-1951^{15}$} \\
\hline AUTOR & FUNÇÃO & $\begin{array}{c}\text { ORIGEM } \\
\text { TEXTO }\end{array}$ & ANO \\
\hline $\begin{array}{l}\text { Brasil P. } \\
\text { Machado }\end{array}$ & $\begin{array}{c}\text { Bacharel em Direito e } \\
\text { Professor catedrático de } \\
\text { História do Brasil da FFCL }\end{array}$ & $\begin{array}{l}\text { Oração de } \\
\text { paraninfo }\end{array}$ & 1940 \\
\hline $\begin{array}{l}\text { Pe. Jesus } \\
\text { Ballarin } \\
\text { Carrera }\end{array}$ & $\begin{array}{c}\text { Filósofo, Teólogo e Professor } \\
\text { catedrático de Filosofia da } \\
\text { FFCL }\end{array}$ & $\begin{array}{l}\text { Oração de } \\
\text { paraninfo }\end{array}$ & 1941 \\
\hline $\begin{array}{c}\text { Liguarú E. } \\
\text { Santo }\end{array}$ & $\begin{array}{c}\text { Eng. Agrônomo e Prof. } \\
\text { catedrático de História e } \\
\text { Filosofia da educação da FFCL }\end{array}$ & $\begin{array}{c}\text { Publicação } \\
\text { Anuário }\end{array}$ & 1941 \\
\hline $\begin{array}{c}\text { Bento M. da R. } \\
\text { Neto }\end{array}$ & $\begin{array}{c}\text { Engenheiro Civil e Prof. } \\
\text { catedrático de História da } \\
\text { América e de Sociologia da } \\
\text { FFCL }\end{array}$ & Aula inaugural & 1942 \\
\hline $\begin{array}{c}\text { Liguarú E. } \\
\text { Santo }\end{array}$ & - & $\begin{array}{l}\text { Oração de } \\
\text { paraninfo }\end{array}$ & 1942 \\
\hline
\end{tabular}

${ }_{15}$ Dados produzidos pelo autor com base nos Anuários da FFCL e da UP de 19401951 . 


\begin{tabular}{|c|c|c|c|}
\hline $\begin{array}{l}\text { Alceu Amoroso } \\
\text { Lima }\end{array}$ & $\begin{array}{l}\text { Bacharel em Direito e Prof. da } \\
\text { Universidade Católica do RJ }\end{array}$ & $\begin{array}{l}\text { Oração de } \\
\text { paraninfo }\end{array}$ & 1943 \\
\hline $\begin{array}{l}\text { José L. } \\
\text { Fernandes }\end{array}$ & $\begin{array}{l}\text { Médico e Prof. catedrático de } \\
\text { Antropologia, Etnografia Geral } \\
\text { e do Brasil da FFCL }\end{array}$ & $\begin{array}{l}\text { Oração de } \\
\text { paraninfo }\end{array}$ & 1943 \\
\hline $\begin{array}{l}\text { Homero B. de } \\
\text { Barros }\end{array}$ & $\begin{array}{c}\text { Bacharel em Direito e Prof. } \\
\text { catedrático de História Antiga } \\
\text { e Medieval da FFCL }\end{array}$ & $\begin{array}{l}\text { Homenagem } \\
\text { póstuma }\end{array}$ & 1943 \\
\hline $\begin{array}{l}\text { Homero B. de } \\
\text { Barros } \\
\end{array}$ & 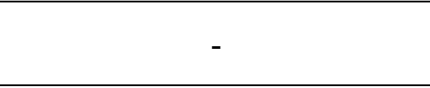 & Aula inaugural & 1946 \\
\hline $\begin{array}{c}\text { Homero de } \mathrm{M} . \\
\text { Braga }\end{array}$ & $\begin{array}{c}\text { Médico e Prof. catedrático de } \\
\text { Biologia da FFCL }\end{array}$ & Aula inaugural & 1947 \\
\hline $\begin{array}{l}\text { Manoel L. } \\
\text { Pinto }\end{array}$ & $\begin{array}{c}\text { Bacharel em Direito e } \\
\text { Professor catedrático de } \\
\text { Política da FFCL }\end{array}$ & Aula inaugural & 1949 \\
\hline $\begin{array}{l}\text { Homero B. de } \\
\text { Barros }\end{array}$ & - & $\begin{array}{c}\text { Assembleia } \\
\text { Universitária }\end{array}$ & 1949 \\
\hline Wilson Martins & $\begin{array}{l}\text { Bacharel em Direito e } \\
\text { Professor de Literatura } \\
\text { Francesa da FFCL }\end{array}$ & Aula inaugural & 1951 \\
\hline
\end{tabular}

Os textos selecionados acima estão associados aos lugares de consagração do grupo da FFCL, pois expressam as intervenções nos atos oficiais de início das atividades acadêmicas e de conclusão de curso. Além disso, os textos das aulas inaugurais e de formatura eram publicados nos anuários da Faculdade. Alguns discursos eram publicados, também, na forma de separatas dos anuários, o que indica a estratégia de ritualização da posição do grupo católico. Em forma de separata foi publicado o discurso de paraninfo de José Loureiro Fernandes, o qual em tom perlocutório sustentava que os intelectuais católicos são confidentes do Criador, ministros do progresso e apóstolos da verdade. No quadro acima, são treze textos escritos por nove autores, dos quais apenas o de Wilson Martins não está associado ao pensamento católico. Entre os demais oito autores, com exceção de Alceu Amoroso Lima, todos eram integrantes do Círculo de Estudos Bandeirantes. Os dados do quadro indicam que, na década de 1940, a FFCL foi controlada pelo pensamento católico, portanto, as dissidências 
não ganhavam espaços nos rituais de consagração. Entretanto, tal domínio parece ser questionado a partir do início da década de 1950, pois é o que atesta a aula inaugural de Wilson Martins. A referência à aula inaugural proferida por Wilson Martins tem a pretensão de indicar a existência de posições divergentes na FFCL, embora com menor força. No entanto, com a federalização da UP abriu-se espaço para o avanço de outras concepções de universidade, assim como de outras visões de filosofia. Tal hipótese não é discutida neste texto, mas novas pesquisas poderão recortar períodos posteriores (décadas de 1960/1970/1980) para avaliar o confronto entre a tradição filosófica católica e outras tendências da filosofia contemporânea (por exemplo, existencialismo, marxismo).

No quadro 2, é possível observar a organização da FCFC. Nessa instituição, o domínio católico não sofre nenhuma contraposição. Se na FFCL, com a federalização da Universidade do Paraná, passaram a existir outras manifestações intelectuais, na FCFC o pensamento católico encontrou um espaço sagrado para sua manifestação e reconhecimento. Tal tendência é o que indicam as aulas inaugurais, orações de formatura e publicações da Revista Humanitas.

\section{Quadro 2}

\begin{tabular}{|c|c|c|c|}
\hline \multicolumn{4}{|c|}{ Alguns discursos acadêmicos da FCFC - 1955-196016 } \\
\hline AUTOR & FUNÇÃO & $\begin{array}{c}\text { ORIGEM } \\
\text { TEXTO }\end{array}$ & ANO \\
\hline $\begin{array}{c}\text { D. M. } \\
\text { D'Elboux }\end{array}$ & Arcebispo de Curitiba & Oração paraninfo & 1955 \\
\hline $\begin{array}{c}\text { Irmão Eulálio } \\
\text { Geraldo }\end{array}$ & $\begin{array}{c}\text { Professor da Faculdade de } \\
\text { Filosofia São Tomás de Aquino } \\
\text { de Uberaba }\end{array}$ & $\begin{array}{c}\text { Publicação } \\
\text { Revista }\end{array}$ & 1956 \\
\hline $\begin{array}{c}\text { Pe. João } \\
\text { Monteiro }\end{array}$ & Professor da FCFC & $\begin{array}{c}\text { Publicação } \\
\text { Revista }\end{array}$ & 1956 \\
\hline $\begin{array}{c}\text { José N. dos } \\
\text { Santos }\end{array}$ & Professor UP e FCFC & Aula inaugural & 1956 \\
\hline
\end{tabular}

16 Dados produzidos pelo autor com base na Revista Humanitas de 1955-1960. 


\begin{tabular}{|c|c|c|c|}
\hline $\begin{array}{l}\text { Ney A. de B. } \\
\text { Braga }\end{array}$ & Prefeito de Curitiba & $\begin{array}{l}\text { Oração de } \\
\text { paraninfo }\end{array}$ & 1956 \\
\hline $\begin{array}{l}\text { Bento M. da R. } \\
\text { Neto }\end{array}$ & Professor das FFCL e FCFC & $\begin{array}{l}\text { Publicação } \\
\text { Revista }\end{array}$ & 1957 \\
\hline $\begin{array}{l}\text { Irmão Eulálio } \\
\text { Geraldo }\end{array}$ & Marista & $\begin{array}{l}\text { Publicação } \\
\text { Revista }\end{array}$ & 1958 \\
\hline $\begin{array}{l}\text { Irmão João de } \\
\text { Deus }\end{array}$ & $\begin{array}{c}\text { Provincial Marista do Brasil } \\
\text { Central }\end{array}$ & $\begin{array}{c}\text { Publicação } \\
\text { Revista }\end{array}$ & 1958 \\
\hline $\begin{array}{l}\text { Raul Moreira } \\
\text { Léllis }\end{array}$ & $\begin{array}{l}\text { Professor da Universidade } \\
\text { Católica do Rio de Janeiro }\end{array}$ & Aula inaugural & 1958 \\
\hline $\begin{array}{c}\text { Liguarú } \\
\text { Espírito Santo }\end{array}$ & Professor das FFCL e FCFC & $\begin{array}{c}\text { Publicação } \\
\text { Revista }\end{array}$ & 1960 \\
\hline $\begin{array}{c}\text { Lauro } \\
\text { Esmanhoto }\end{array}$ & $\begin{array}{c}\text { Diploma de professor } \\
\text { normalista; Professor de } \\
\text { Administração escolar e } \\
\text { educação comparada da FFCL } \\
\text { e FCFC }\end{array}$ & $\begin{array}{l}\text { Publicação } \\
\text { Revista }\end{array}$ & 1960 \\
\hline
\end{tabular}

Os dados do quadro 1 indicam que na FFCL predominava a presença do laicato católico. Já na FCFC o poder estava pulverizado entre laicato, irmãos maristas e o próprio Arcebispo de Curitiba. Tais características evidenciam que, nas duas instituições, a Igreja Católica contava com a colaboração do laicato católico, porém, na FCFC, o clero mantinha maior controle sobre as atividades acadêmicas, por consequência sobre os intelectuais católicos leigos. O caráter confessional da FCFC é um aspecto importante para explicar essa particularidade em relação à FFCL. A própria criação da FCFC, em agosto de 1950, seis meses antes da federalização da UP, expressa que o grupo católico paranaense dirigiu sua ação em defesa da Universidade Católica. Por outro lado, a ênfase na criação da Universidade Católica ${ }^{17}$ não representou o cancelamento dos esforços para manter o pensamento católico na Universidade Federal do Paraná, porém, houve relativização do pensamento católico na FFCL.

Os quadros anteriores evidenciam a posição social daqueles que coordenavam os rituais de consagração. Segundo Bourdieu (2008, p. 98),

17 A Universidade Católica do Paraná foi criada em 1959. 
"falar em rito de instituição é indicar que qualquer rito tende a consagrar ou a legitimar, isto é, a fazer desconhecer como arbitrário e a reconhecer como legítimo e natural um limite arbitrário". A rigor, o lugar ocupado pelos locutores é um aspecto instigante para se discutir neste artigo. Nesse sentido, a hipótese bourdieusiana de linguagem autorizada como condição de legitimidade das intervenções dos católicos, nesses rituais de consagração, mostra-se relevante. A vinculação institucional daqueles que proferem aulas inaugurais, orações de paraninfos e publicam nos anuários e revista, caracteriza-se como uma chave de leitura, uma vez que "o poder das palavras é apenas o poder delegado do porta-voz cujas palavras $[\ldots]$ constituem no máximo um testemunho, um testemunho entre outros da garantia de delegação de que ele está investido" (BOURDIEU, 2008 , p. 87). Neste momento, nossa narrativa acentua o lugar institucional de enunciação, pois pretende sustentar que a ocupação dos rituais de consagração, próprios da Faculdade de Filosofia, consistiu em uma estratégia de descrição e prescrição do mundo universitário e do mundo social. Desse modo, retiramos a centralidade analítica da própria palavra (enunciação) e da retórica (modo de enunciação) e transferimos para o sujeito da enunciação, isto é, ao porta-voz das palavras. Em termos próximos aos de Bourdieu, enfatizamos que o reconhecimento da eficácia das palavras está nas condições sociais, portanto, em um conjunto de condições socialmente reconhecidas, como por exemplo locutor, situação e linguagem adequados.

As ações desses professores, nos rituais da Faculdade de Filosofia, objetivavam descrever e prescrever uma condição ou um comportamento social. Dessa forma, "o porta-voz autorizado consegue agir com palavras em relação a outros agentes e, por meio de seu trabalho, agir sobre as próprias coisas [...]" (BOURDIEU, 2008, p. 89). Tal situação constitui uma espécie de magia social. E tal magia acontece à medida que a fala do portavoz "concentra o capital simbólico acumulado pelo grupo que lhe conferiu o mandato e do qual ele é, por assim dizer, o procurador" (BOURDIEU, 2008, p. 89). Em síntese, os conceitos de linguagem autorizada e rituais de instituição são pertinentes para interpretar as intervenções dos católicos nesses atos de consagração, pois além das condições litúrgicas (modo de dizer), assume sentido fundamental a assertiva de que "a delegação de 
autoridade confere sua autoridade ao discurso autorizado" (BOURDIEU, 2008, p. 91). Além disso, "o verdadeiro milagre produzido pelos atos de instituição reside no fato de que eles conseguem fazer crer aos indivíduos consagrados que eles possuem uma justificação para existir, ou melhor, que sua existência serve para alguma coisa" (BOURDIEU, 2008, p. 106).

A ênfase ao lugar institucional do locutor não cancela a discussão a respeito dos sentidos e significados da própria enunciação, isto é, sobre as temáticas recorrentes nas descrições e prescrições desses locutores. Nos quadros seguintes ( 3 e 4) são associados autores e temáticas tratadas nos textos proferidos e publicados nas FFCL e FCFC.

\section{Quadro 3}

\begin{tabular}{|c|c|c|}
\hline \multicolumn{3}{|c|}{ Temáticas dos discursos da FFCL-1940-1951 ${ }^{18}$} \\
\hline AUTOR & TEMÁTICA DO TEXTO & ANO \\
\hline $\begin{array}{c}\text { Brasil Pinheiro } \\
\text { Machado }\end{array}$ & Função da Faculdade de Filosofia & 1940 \\
\hline Pe. Jesus B. Carrera & Filosofia, ciência e magistério & 1941 \\
\hline Liguarú Espírito Santo & Marcelino Champagnat & 1941 \\
\hline Bento M. da R. Neto & Sociologia católica & 1942 \\
\hline Liguarú Espírito Santo & Filosofia, catolicismo e magistério & 1942 \\
\hline Alceu Amoroso Lima & Filosofia, catolicismo e magistério & 1943 \\
\hline $\begin{array}{c}\text { José Loureiro } \\
\text { Fernandes }\end{array}$ & Missão do laicato católico & 1943 \\
\hline Manoel Lacerda Pinto & Pe. Jesus Ballarin Carrera & 1943 \\
\hline Homero B. de Barros & Prof. José F. M. Guérios & 1943 \\
\hline Homero B. de Barros & Humanismo católico & 1946 \\
\hline $\begin{array}{c}\text { Homero de Melo } \\
\text { Braga }\end{array}$ & Formação médica e humanismo católico & 1947 \\
\hline Manoel Lacerda Pinto & Rui Barbosa e catolicismo & 1949 \\
\hline Homero B. de Barros & Caráter humanístico da universidade & 1949 \\
\hline Wilson Martins & Universidade e Ortega y Gasset & 1951 \\
\hline
\end{tabular}

18 Dados produzidos pelo autor com base nos Anuários da FFCL e da UP de 1940-1951.

19 Dados produzidos pelo autor com base na Revista Humanitas de 1955-1960. 


\section{Quadro 4}

\begin{tabular}{|c|c|c|}
\hline \multicolumn{3}{|c|}{ Temáticas dos discursos da FCFC - 1955-1960 } \\
\hline AUTOR & TEMÁTICA DO TEXTO & ANO \\
\hline D. Manuel D'Elboux & Missão do docente & 1955 \\
\hline Irmão Eulálio Geraldo & Natureza da sociedade & 1956 \\
\hline Pe. João Monteiro & Tomás de Aquino & 1956 \\
\hline José N. dos Santos & Igreja, escola e imprensa & 1956 \\
\hline Ney A. de B. Braga & Igreja, ensino superior e nação & 1956 \\
\hline Bento M. da R. Neto & Universidade e Igreja Católica & 1957 \\
\hline Irmão Eulálio Geraldo & Tomás de Aquino e Filosofia da Educação & 1958 \\
\hline Irmão João de Deus & Mentalidade espiritual do Brasil e & 1958 \\
\hline Raul Moreira Léllis & educação & 1958 \\
\hline Liguarú Espírito Santo & Santo Agostinhóno e educação & 1960 \\
\hline Lauro Esmanhoto & Magistério e ética & 1960 \\
\hline
\end{tabular}

Em regra, as palavras-chave das intervenções desse professores são universidade, faculdade de filosofia, filosofia católica, missão social do laicato. Esses eixos são depreendidos do conjunto da discussão dos textos ou do próprio título do texto de cada autor. Os debates em torno da função social da universidade e dos intelectuais estão fundamentados na tradição filosófica católica. Associada aos conceitos de linguagem autorizada e rito de instituição, está a categoria força da representação, a qual permite problematizar a linguagem comum utilizada pelo grupo que proferiu aulas inaugurais, orações de paraninfos e fez publicações em periódicos das referidas faculdades. A cruzada dos indivíduos que ocupavam os rituais de consagração consistia em descrever e prescrever o mundo social e o próprio mundo universitário. Nesses termos, travavam "a luta entre representações, quer no sentido de imagens mentais, quer naquele outro sentido de manifestações sociais destinadas a manipular as imagens mentais" (BOURDIEU, 2008, p. 108). As representações do mundo social, construídas pelos católicos ao discutirem o papel social da universidade e dos intelectuais, ganham um sentido pleno ao serem chanceladas pela autoridade reconhecida. A rigor, conforme Bourdieu (BOURDIEU, 2008, p. 109), "pelo fato de dizer as coisas com autoridade, 
ou seja, diante de todos e em nome de todos, pública e oficialmente, ele as destaca do arbitrário, sancionando-as, santificando-as e consagrando-as, fazendo-as existir como sendo dignas de existir, ajustadas à natureza das coisas". Dessa forma, "o ato de categorização, quando consegue fazer-se reconhecer ou quando é exercido por uma autoridade reconhecida, exerce por si só um poder" (BOURDIEU, 2008, p. 110).

As intervenções dos locutores indicados nos quadros anteriores descreviam e prescreviam um conjunto de elementos do mundo social. Entretanto, alguns professores trataram, de modo específico, do problema da função social da Faculdade de Filosofia e dos intelectuais. Brasil Pinheiro Machado, ao dirigir-se à primeira turma de bacharéis, formada na FFCL, sustentava: "somos todos combatentes da mesma batalha, perseguidores da mesma finalidade que é a criação de um clima propício ao desabrochar de uma verdadeira liderança intelectual, dentro do desordenado ambiente da cultura nacional" (MACHADO, 1940, p. 42). Atrelado ao papel de liderança deveria estar, na definição de Pe. Jesus Ballarin Carrera, o "ressoar em vosso ouvido e ecoar em vossa alma como um estímulo criador de intensa vida intelectual, o imperativo agostiniano: amar a inteligência; amá-la intensamente. Intellectum valde ama" (CARRERA, 1941, p. 4849). A direção intelectual, propalada por Pinheiro Machado, perpassava por profunda formação científica e filosófica, isto é, a intervenção cultural/ política estava vinculada à máxima: "amai a 'ciência' e a 'harmonia das ciências' e acima da ciência amai 'a sabedoria' e a 'harmonia das Sabedorias"” (CARRERA, 1941, p. 52).

A noção de missão intelectual propugnada pelo grupo das Faculdades de Filosofia consistia no

entendimento norteado pela verdade; [n]a verdade sujeita à moral; [n] as paixões controladas pelo entendimento e pela vontade: tudo iluminado, dirigido, elevado pela Religião: eis o homem completo, o homem ideal. Nele a razão ilumina, a imaginação enleva, o coração vivifica, a Religião diviniza (CARRERA, 1941, p. 54).

A formação intelectual estava atrelada à missão do ensino superior. Tal relação é atestada por Loureiro Fernandes (1943, p. 66) ao indicar que, em decorrência da crescente desorganização da sociedade após a Primeira 
Guerra, "não cessavam de clamar por auxílios mais eficientes às Instituições Universitárias como um dos supremos recursos para a salvação das elites". Em seguida, asseverava Fernandes (1943, p. 66), "a formação das elites é o dever precípuo que às organizações universitárias incumbe e de modo preponderante às Faculdades de Filosofia, por serem estas as orientadoras da verdadeira instrução e educação [...]". Na avaliação de Brasil Machado (1940, p. 42), "ao par da necessidade da formação de técnicos, cresce, no Brasil, a necessidade da formação dessas 'elites' intelectuais [...]". Por outro lado, denunciava que "não exerceram as escolas superiores [...] a função de recriar e disciplinar a cultura nacional, e, no entanto, só pelas escolas superiores é possível tal função" (MACHADO, 1940, p. 42). Indagava-se sobre quais modelos de escolas atingiriam tal tarefa. Não seria nas escolas de formação profissional. Entretanto, enunciava: "somente as Faculdades de Filosofia, como núcleos irradiadores dentro de uma organização universitária, podem desempenhar tal missão, porque só elas têm contextura própria, o tratamento desinteressado de aplicação imediata [...]" (MACHADO, 1940, p. 43). Em direção semelhante apregoava Loureiro Fernandes (1943, p. 67): "no justo desempenho de nobre função educadora [...], as Faculdades de Filosofia tornar-se-ão [...] poderosos agentes da nossa unidade 'ao promover o instinto comum de brasilidade e a universalização do sentimento nacional"”.

As Faculdades de Filosofia deveriam formar professores, humanistas, historiadores, geógrafos, físicos, matemáticos, biólogos, filósofos. Nesse aspecto, uma das tarefas tinha "caráter utilitário, digamos a exclusiva feição prática [...] destinada ao professorado secundário e à alta técnica científica aplicada" (FERNANDES, 1943, p. 67-68). Outra tarefa seriam os estudos "básicos para a grandeza futura do povo brasileiro" (FERNANDES, 1943, p. 68). Na denominação de Fernandes (1943, p. 68), "a finalidade desses estudos é muito mais alta e [...] sempre haverá e é mister que haja para a verdadeira grandeza de um povo, muito mais que a burguesia comerciante [...], uma elite, numerosas elites de pensadores, de sonhadores idealistas, a serviço do bem comum". Na conclusão da oração de paraninfo, Brasil Pinheiro Machado (1940, p. 44, grifo nosso), rememorou a sentença proferida à primeira turma de bacharéis da Faculdade de Filosofia de São Paulo: "encerrastes definitivamente um ciclo de nossa existência para dar início a outro: o da nossa maioridade intelectual!". 
Ao dirigir-se aos formandos, enfatizava Fernandes (1943, p. 70), “a perseverança no estudo consolidará a vossa personalidade [...]. Títulos nobiliárquicos, que para os cultores da Ciência, consistem em ser 'Confidentes do Criador, Ministros do Progresso e Sacerdotes da Verdade". O sentido de confidente do criador sustenta-se porque "só o verdadeiro cientista pode compreender algo dessa linguagem misteriosa que Deus escreveu na natureza [...]. A ciência, afinal, não é mais do que a procura, pelos homens, do nome que Deus deu às coisas do universo" (FERNANDES, 1943, p. 70-71). Tal sentido também estava presente no discurso de Jesus Ballarin Carrera (1941, p. 53): "o pensamento humano [...] deve encontrar-se em todas suas pesquisas, em todas as avenidas com a idéia e a realidade divina. Deve necessariamente encontrar-se com o Deus do Cristianismo [...], verdade infinita, inteligência subsistente". Em outros termos, confidente do Criador toma por princípio que "deve reinar harmonia absoluta entre o Pensamento, Autor da Realidade, e o pensamento - reflexo dos entes que forma e produz a verdade criada" (CARRERA, 1941, p. 53).

A tarefa intelectual do grupo católico perpassava também pelo ministério do progresso. Essa assertiva objetivava confrontar-se com os materialistas que defendiam o progresso, porém sem vinculação aos princípios metafísicos da Igreja Católica. Desse modo, um confidente do Criador deveria ser um ministro do progresso do mundo social. Havia associação, na avaliação dos católicos, entre progresso material e progresso moral. Sobre tal aspecto manifestava-se Loureiro Fernandes (1943, p. 71): "medir a importância de uma Ciência apenas pela sua utilidade prática é um crime contra a inteligência, e consequentemente contra o progresso humano". O sentido de ministro do progresso consistia no controle a ser exercido pela filosofia sobre a ciência aplicada. A esse respeito pronunciava-se Fernandes (1943, p. 71): "sobram-lhes [...] razões aos que, persuadidos da errônea distinção entre ciência teórica e ciência prática, não admitem nem toleram o excessivo culto prestado a esta, com detrimento e até desprezo daquela". As passagens acima podem ser aproximadas do enunciado de Jesus Ballarin Carrera (1941, p. 51): "amai a ciência, mas evitai ainda o 'fetichismo' da ciência que professou o cientismo. [...] Sabeis não ser a ciência valor único, nem mesmo valor absoluto e supremo. A ciência é apenas a "escola primária do espírito"”. Em seguida, apregoa 
que "o pensamento humano, a razão humana é uma força viva que busca seu ponto de apoio e o seu fim; o princípio e o fim da inteligência é Deus [...]" (CARRERA, 1941, p. 52).

O intelectual católico deveria ser confidente do Criador, ministro do progresso, mas também apóstolo da Verdade. O principal sentido estabelecido ao ato linguístico "apóstolo da verdade" consistiu na afirmação de que "assumis o nobre compromisso de contribuir com o vosso saber e talento para preservar da desagregação a nossa cultura, a lusobrasileira cujas raízes se vão prender à unidade filosófica helênico-cristã" (FERNANDES, 1943, p. 72). Em termos precisos, a responsabilidade com a verdade seria substituir a concepção de ciência, segundo a qual "só há um objeto de observação, os fatos, e uma só noção deduzida da observação, as leis, por aquela que compreende a ciência como conhecimento tanto dos fenômenos (ciências positivas) como da substância (ciência metafísica)" (FERNANDES, 1943, p. 73, grifo do autor).

Por fim, arrematava Fernandes (1943, p. 74):

O Sacerdócio da Verdade, sagrado ministério, é que dá a esta Faculdade alta expressão intelectual ao traduzir um sentimento coletivo, uma corrente de opinião um roteiro de atividades cujo objetivo é o de constituir uma verdadeira escola. Escola na elevada "função de criar, recriar e disciplinar os altos atributos da cultura humana e de perpetuar seus elementos constitutivos". Escola, no sentido de vigoroso núcleo irradiador de cultura, a despertar inteligências adestrando-as para os futuros trabalhos de investigação científica, sem o ônus tremendo de um exclusivo e laborioso autodidatismo.

As Faculdades de Filosofia deveriam cumprir, na avaliação do laicato católico, a missão de articular o ensino superior paranaense. A condição de confidentes do Criador, ministros do progresso e apóstolos da verdade era o que se esperava dos intelectuais católicos. Tais atividades consistiam na principal atribuição das Faculdades de Filosofia. Em aula inaugural de 1946, Homero de Barros (1946, p. 40) professou que a FFCL “[...] bem merece as preferências com que a distingue a juventude universitária porque desempenha função social e cristã de inatingida relevância nos destinos nacionais". 
O projeto das Faculdades de Filosofia deveria promover a formação humanista do jovem paranaense, no entanto, tratava-se do humanismo cristão, pois é assim que o compreendia Barros (1946, p. 40): "Maritain frisa o caráter teocêntrico do humanismo, para que este [...] não [se] confunda com o humanismo do Renascimento ou com o da Reforma, que foram antropocêntricos por excelência". Homero de Barros (1946, p. 45) asseverava que o "interesse fundamental deve consistir em que todo o desenvolvimento, que vai da educação inicial até à cultura superior, seja dirigido pelo mesmo princípio de formação humanística conveniente para formar o verdadeiro cristão [...]". A rigor, para ele, "a formação humanística não se concilia com o ensino leigo [laico] [...]. E nem com o ensino religioso facultativo, que é fórmula desfavorável ao exercício do apostolado intelectual, tão urgente na escola quanto nos colégios e nas universidades" (BARROS, 1946, p. 46).

O espírito irradiador do ensino superior do Paraná deveria nascer das Faculdades de Filosofia, pois “o grandioso empreendimento só atingirá seu objetivo se não se limitar apenas à obra de erudição e cultura, mas se desempenhar realmente a grande missão de orientação espiritual, acumulando as reservas de resistência das novas gerações" (BARROS, 1946, p. 46). Em direção contrária ao exposto acima, ponderava Barros, "a Universidade não virá senão fabricar técnicos para a condenável 'civilização da máquina', uma das causas mais decisivas da 'indignidade do mundo moderno"” (BARROS, 1946, p. 46).

Por fim, conclamava:

[...] fica o apelo à mocidade da Faculdade de Filosofia para que contribua, a todo poder, na formação do espírito universitário pelos ideais do humanismo integral, buscando na cultura superior um instrumento de restauração dos valores eternos, um sentido cristão e intangível da vida, meio de contribuir para que a sociedade não se distancie de Deus (BARROS, 1946, p. 46).

As intervenções do grupo católico objetivam conformar uma visão do mundo social, assim como o próprio mundo social. Essas atuações podem ser interpretadas como a ação política dos católicos. As ações 
do grupo católico têm "como objetivo produzir e impor representações do mundo social capazes de agir sobre esse mundo, agindo sobre as representações dos agentes a seu respeito" (BOURDIEU, 2008, p. 117). As palavras proferidas nos rituais de consagração das Faculdades de Filosofia são enunciados performativos que pretendem

fazer acontecer o que enunciam; [contribuir] praticamente para a realidade do que anunciam pelo fato de enunciá-los, de prevê-los e de fazê-los prever; por torná-los concebível e sobretudo crível, criando assim a representação e a vontade coletivas em condições de contribuir para produzi-los (BOURDIEU, 2008, p. 118).

Os representantes da comunidade acadêmica das Faculdades de Filosofia, ao proferirem que o laicato deveria ser confidente do Criador, ministro do progresso e apóstolo da verdade, tomavam esses léxicos em sentido descritivo, mas principalmente com caráter prescritivo, pois pretendiam exercer "um efeito de teoria tendente a favorecer o acontecimento daquilo que anuncia" (BOURDIEU, 2008, p. 124). Nos termos de Bourdieu (2008, p. 110), é a tentativa de "dar existência à coisa nomeada". E tal ato será "bem-sucedido quando aquele que efetua for capaz de fazer reconhecer por sua palavra o poder que tal palavra garante por uma usurpação provisória ou definitiva, qual seja o poder de impor uma visão e uma nova divisão do mundo social" (BOURDIEU, 2008, p. 111). Em síntese, em nome da força da representação movem-se os intelectuais católicos, pois por meio de "enunciados performativos pretendem fazer acontecer o que eles enunciam” (BOURDIEU, 2008, p. 112).

A formação acadêmica nas Faculdades de Filosofia do Paraná estava conformada pela tradição católica, cuja principal preocupação era conciliar os progressos da ciência moderna com a filosofia tomista. Nesse sentido, durante as décadas de 1940 e 1950, o caráter acadêmico do estudante que se preparava para exercer uma atividade de liderança na sociedade, seja na condição de professor ou profissional liberal, ganhava forte contorno do pensamento católico. No primeiro item deste texto, a pretensão foi evidenciar a hipótese de que os intelectuais católicos estabeleceram as 
Faculdades de Filosofia como uma estratégia de luta pela conformação do mundo universitário e do mundo social paranaense. Já neste item, a intenção foi discutir as estratégias sistematizadas pelos católicos, no interior das Faculdades de Filosofia, visando objetivar representações sobre a função social da universidade e dos intelectuais. Nesse sentido, elegemos como categorias analíticas a linguagem autorizada, os ritos de instituição e a força da representação para problematizar as ações políticas do grupo católico, pois observamos que seus membros controlaram os rituais de consagração (aula inaugural, oração de paraninfo e publicação). Portanto, esses agentes, ao dominarem tais espaços sociais, promoveram uma ação política, isto é, "por fazerem parte do mundo social, têm um conhecimento desse mundo, podendo-se então agir sobre o mundo social agindo-se sobre o conhecimento que os agentes têm dele" (BOURDIEU, 2008, p. 117).

\section{Considerações finais}

O objetivo deste texto foi problematizar a ação dos intelectuais católicos em defesa do Ensino Superior no Paraná das décadas de 1940 e 1950. Sob o pano de fundo do movimento da Igreja Católica que visava manter-se presente na sociedade contemporânea, assim como lançarse contra seus adversários, este texto discutiu os sentidos da educação superior na cruzada intelectual dessa instituição religiosa. A criação de instituições de ensino superior foi uma das estratégias políticas e culturais da Igreja Católica, na qual contou com a colaboração contínua de lideranças intelectuais de diferentes cidades do Brasil. No Paraná, desde o final da década de 1920, os católicos estiveram comprometidos com o projeto cristianização do mundo social paranaense. No final dos anos de 1930 foi estabelecida a FFCL, a qual permitiu que o grupo católico circulasse e divulgasse a filosofia tomista entre parcela significativa dos acadêmicos paranaenses, pois, com a criação da Universidade do Paraná (1946), houve investimento na tentativa de expansão da visão de mundo católica a todos os ambientes das instituições de ensino superior. Na década de 1950, os católicos controlavam a FFCL e a FCFC. A federalização da Universidade do Paraná (1950) não representou a supressão da doutrina católica dessa instituição, pois é possível afirmar que o pensamento católico se manteve 
com muita força, uma vez que na década de 1950 a reitoria da Universidade e a direção da FFCL estavam sob a direção de Flavio de Lacerda e Homero de Barros, ambos atrelados ao grupo católico. Já a criação da FCFC representou o início do processo de consolidação do ensino superior confessional que culminou na Universidade Católica do Paraná.

Ao discutir o problema do ensino superior católico no Paraná, este texto fez referência aos paradigmas intelectuais, epistémé, às correntes filosóficas que interferiram nas representações, nas visões de mundo do grupo católico, assim como às razões particulares do contexto paranaense que estavam associadas ao processo de organização da FFCL e FCFC. O primeiro aspecto diz respeito à pretensão do grupo em articular ciência moderna e filosofia católica. O segundo se refere ao processo de organização do laicato católico no Paraná que resultou na criação das duas Faculdades de Filosofia, nas quais se buscou conformar um projeto de educação de bacharéis e licenciados, sob a égide da ciência moderna e da metafísica católica.

A partir dos rituais, isto é, das aulas inaugurais e orações de paraninfos, foi possível observar que o grupo católico manteve o controle das principais atividades acadêmicas da FFCL e FCFC. Tal aspecto evidencia que a doutrina católica conformou a direção ideológica dos cursos de humanidades existentes no Paraná durante as décadas de 1940 e 1950. Portanto, a hipótese de que o laicato católico exerceu o papel de organizador da cultura ao estabelecer a FFCL e a FCFC mostra-se útil para interpretar a ação dos intelectuais paranaenses que estavam envolvidos com o ensino superior, particularmente, à medida que esse grupo apregoava a si mesmo as funções de confidente do Criador, ministro do progresso e sacerdote da verdade, caracterizando uma visão autoritária de sociedade ao enunciar que apenas ele poderia conduzir o mundo social em direção ao progresso material e moral.

\section{Referências}

ANDRADE, Maria Lúcia de. Dario Vellozo e a escola moderna: a renovação do pensamento educacional no Paraná. In: VIEIRA, Carlos Eduardo (Org.). Intelectuais, educação e modernidade no Paraná (18861964). Curitiba: UFPR, 2007. p. 191-215. 
ANUÁRIO da Faculdade de Filosofia, Ciências e Letras do Paraná. Curitiba, 1940-1943.

ANUÁRIO da Universidade do Paraná. Curitiba, 1946-1951.

BALHANA, Carlos Alberto. Idéias em confronto. Curitiba: Grafipar, 1981.

BARROS, Homero Batista de. Preleção inaugural do ano letivo de 1946, na Faculdade de Filosofia, Ciências e Letras do Paraná: formação humanística. Anuário da Universidade do Paraná, Curitiba, s. n., p. 40-46, 1946.

BENCOSTTA, Marcus Levy Albino. Igreja e poder em São Paulo: D. João Batista Corrêa Nery e a romanização do catolicismo brasileiro (19081920). 1999. 309 f. Tese (Doutorado em História Social)-Universidade de São Paulo, São Paulo, 1999.

BONA JUNIOR, Aurélio; VIEIRA, Carlos Eduardo. O discurso da modernidade nas conferências educacionais na década de 1920 no Paraná. In: VIEIRA, Carlos Eduardo (Org.). Intelectuais, educação e modernidade no Paraná (1886-1964). Curitiba: UFPR, 2007. p. 13-40.

CAMPOS, Névio de. Intelectuais e igreja católica no Paraná (1926-1938). Ponta Grossa: UEPG, 2010a.

. Intelectuais paranaenses e as concepções de universidade (1892-1950). Curitiba: UFPR, 2008.

. O papel do clero e do laicato católico no processo de constituição da Universidade Católica do Paraná (1959). Cadernos de História da Educação. Uberlândia, v. 9, n. 1, p. 187-205, jan./jun. 2010 b.

. Faculdade Católica de Filosofia de Curitiba: insígnia do ensino superior católico paranaense (1950). Revista Contrapontos. Itajaí, v. 11, n. 1, p. 53-61, jan./abr. 2011a.

. Debate sobre o ensino religioso na capital paranaense: entre a tribuna e a imprensa (1922-1931). Educação em Revista. Belo Horizonte, v. 27, n. 1, p. 65-91, abr. 2011 b.

CARRERA, Jesus Ballarin. Oração de paraninfado da turma de 1941. Anuário da Faculdade de Filosofia, Ciências e Letras do Paraná, Curitiba, s. n., p. 45-54, 1941.

CARVALHO, Marta Maria Chagas de. Molde nacional e fôrma cívica: higiene, moral e trabalho no projeto da Associação Brasileira de Educação (1924-1931). Bragança Paulista: EUSF, 1998. 
DIAS, Romualdo. Cor unum et anima uma: A doutrina católica sobre a autoridade no Brasil (1922-1935). 1993. 285 f. Tese (Doutorado em Lógica e Filosofia da Ciência)-Universidade Estadual de Campinas, Campinas, 1993.

FERNANDES, José Loureiro. Discurso aos bacharéis de 1943. Anuário da Faculdade de Filosofia, Ciências e Letras do Paraná, Curitiba, s. n., p. 65-75, 1943.

FRESSATO, Soleni Terezinha. Pela catolicização da elite curitibana: o projeto intelectual do Círculo de Estudos "Bandeirantes" - CEB (19291945). 2003. 96 f. Dissertação (Mestrado em História)-Universidade Federal do Paraná, Curitiba, 2003.

GRAMSCI, Antonio. Cadernos do cárcere. v. 2. Rio de Janeiro: Civilização Brasileira, 2001.

HANICZ, Teodoro. Modernidade, religião e cultura: o Círculo de Estudos Bandeirantes e a restauração do catolicismo em Curitiba (1929-1959). 2006. Tese (Doutorado em Ciências da Religião)-Pontifícia Universidade Católica de São Paulo, São Paulo, 2006.

MACHADO, Brasil Pinheiro. Oração de paraninfo da turma de 1940. Anuário da Faculdade de Filosofia, Ciências e Letras do Paraná, Curitiba, s. n., p. 41-44, 1940.

MANOEL, Ivan Aparecido. Igreja e educação feminina (1859-1919): uma face do conservadorismo. São Paulo: UNESP, 1996.

MARCHI, Euclides. A igreja e a questão social: o discurso e a práxis do catolicismo no Brasil (1850-1915). 1989. Tese (Doutorado em História)Universidade de São Paulo, São Paulo, 1989.

MEHL, Herley. Dados estatísticos e a opção: curso de filosofia. Revista Humanitas. Curitiba, ano 5, n. 5, p. 33-44, 1960.

MICELI, Sérgio. A elite eclesiástica brasileira. Rio de Janeiro: Bertrand Brasil, 1974.

MORENO, Jean Carlos. Inventando a escola, inventando a nação: discursos e práticas em torno da escolarização paranaense (1920-1928). 2003. 140 f. Dissertação (Mestrado em Educação)-Programa de Pós- 
Graduação em Educação, Universidade Federal do Paraná, Curitiba, 2003. PADIAL, Elyane. As propostas de Lysimaco Ferreira da Costa para a instrução pública paranaense no período de 1920-1928. 2008. $147 \mathrm{f}$. Dissertação (Mestrado em Educação)-Programa de Pós-Graduação em Educação, Universidade Estadual de Maringá, Maringá, 2008.

REVISA HUMANITAS (Faculdade Católica de Filosofia de Curitiba). Curitiba, 1956-1960.

RODRIGUES DA SILVA, Helenice. A história intelectual em questão. In: LOPES, Marcos Antonio (Org.). Grandes nomes da história intelectual. São Paulo: Contexto, 2003. p. 15-25.

ROMANO, Roberto. Brasil: igreja contra estado (crítica ao populismo católico). São Paulo: Koirós, 1991.

SALEM, Tânia. Do Centro Dom Vital a universidade católica. In: SCHWARTZMAN, S. (Org.). Universidades e instituições científicas no Rio de Janeiro. Brasília: CNPq, 1982. p. 97-134.

STRANG, Bernadete de Lourdes. O saber e o credo: os intelectuais católicos e a doutrina da Escola Nova. 2008. 222 f. Tese (Doutorado em Educação)-Programa de Pós-Graduação em Educação, Pontifícia Universidade Católica do Rio de Janeiro, Rio de Janeiro, 2008.

TRINDADE, Etelvina Maria de Castro. Clotildes ou marias: mulheres de Curitiba na Primeira República. Curitiba: Fundação Cultural, 1996.

VIEIRA, Carlos Eduardo; MARACH, Caroline Baron. Escola de mestre único e escola serena: realidade e idealidade no pensamento de Erasmo Pilotto. In: VIEIRA, Carlos Eduardo (Org.). Intelectuais, educação e modernidade no Paraná (1886-1964). Curitiba: UFPR, 2007, p. 269-289. WESTPHALEN, Cecília Maria. Faculdade de Filosofia e Letras do Paraná - 50 anos. Curitiba: SBPH-PR, 1988.

Data de registro: 08/11/2011 Data de aceite: $21 / 03 / 2012$ 